\title{
Early identification of hypoxic-ischemic encephalopathy by combination of magnetic resonance (MR) imaging and proton MR spectroscopy
}

\author{
LILI GUO $^{1}$, DEHANG WANG ${ }^{2}$, GENJI BO ${ }^{1}$, HUI ZHANG $^{1}$, WEIJING TAO $^{1}$ and YING SHI ${ }^{1}$ \\ ${ }^{1}$ Department of Magnetic Resonance Imaging, Huai'an First People's Hospital Affiliated to Nanjing Medical University, \\ Huai'an, Jiangsu 223300; ${ }^{2}$ Department of Radiology, First Affiliated Hospital, \\ Nanjing Medical University, Nanjing, Jiangsu 210029, P.R. China
}

Received May 5, 2015; Accepted August 11, 2016

DOI: $10.3892 /$ etm. 2016.3740

\begin{abstract}
Brain damage following a perinatal hypoxic-ischemic encephalopathy (HIE) can be diagnosed by different techniques. The aim of the present study was to combine magnetic resonance (MR) imaging with proton MR spectroscopy in HIE diagnosis and to evaluate their correlation with outcome. A prospective observational cohort study was performed between February 2012 and February 2013. Consecutive newborns, 24 full-term neonates with HIE (mild to moderate and severe group) and 5 normal neonates, were included. Two sequential MR studies were performed; a conventional MR imaging for observation in T1 weighted image (WI) and T2WI, and proton MR spectroscopy for observation in the left or right basal ganglia and thalamus. MR images were assessed and scored by two neuroradiologists who were blinded to the clinical condition of the infants. The mild to moderate group $(n=13)$ and severe group $(n=11)$ were similar in the visualization of punctate hyperintensity lesions on T1WI and brain edema on T2WI. The differences of $\mathrm{N}$-acetylaspartate/creatine $(\mathrm{Cr})$, choline/Cr and lactate/Cr in the basal ganglia and thalamus in the HIE group were significantly different $(\mathrm{P}<0.05)$ compared with the control group, while no significant difference was identified between the mild to moderate and severe group $(\mathrm{P}>0.05)$. In conclusion, MR spectroscopy is a complementary tool for the diagnosis of HIE.
\end{abstract}

Correspondence to: Dr Dehang Wang, Department of Radiology, First Affiliated Hospital, Nanjing Medical University, 300 Guangzhou Road, Nanjing, Jiangsu 210029, P.R. China E-mail: wangdehang8@126.com

Key words: hypoxic-ischemic encephalopathy, magnetic resonance imaging, diffusion weighted imaging, proton magnetic resonance spectroscopy, neonate

\section{Introduction}

Hypoxic-ischemic encephalopathy (HIE), secondary to perinatal asphyxia, is a primary cause of pediatric mortality and morbidity, and results in neurologic outcomes, such as cerebral palsy, mental retardation and epilepsy (1). Timely prognostic information is important in counseling parents and in determining the appropriate level of treatment. Consequently, reliable early examinations are urgently required. During the last decade, advances have been achieved in the field of diagnosis and prognosis of HIE (2).

Clinicians use prognostic tests, including magnetic resonance (MR) imaging (MRI), to help determine the prognosis and decide whether to consider treatment withdrawal. It is understood that MRI serves an increasing important role for imaging the neonatal brain (3-6). However, proton MR spectroscopy has been developed for clinical use. This allows real-time analyses of the metabolites in the human brain. It has been widely reported that the potential utility of proton MR spectroscopy could reveal brain ischemic injuries in asphyxiated neonates earlier than T1- or T2-weighted MR imaging (7-11). Whether MR spectroscopy prior to conventional MR imaging should be used in the early diagnosis of neonate with HIE remains unknown. How to select the imaging technique between the two methods in different conditions? Therefore, the aim of the present study was to evaluate the value of MR spectroscopy and MR imaging for the diagnosis of HIE.

\section{Subjects and methods}

Subject selection. The protocol was approved by the review board of Nanjing Medical University (Nanjing, China). Participants in the study were voluntary; the study was performed after obtaining informed consent from the infants' parents. In this study, 24 full term infants ( 17 males, 7 females; age range,0-15 days) with HIE were collected from the Department of Pediatrics in Huai'an First People's Hospital Affiliated to Nanjing Medical University (Huai'an, China) between February 2012 and February 2013. All of the cases had perinatal asphyxia, and were defined as having at least three of the following criteria (12): i) Fetal heart rate abnormalities; 
ii) meconium staining of amniotic fluid; iii) delayed onset of respiration; iv) early postnatal blood $\mathrm{pH}$ level <7.1; v) Apgar score at 5 min of $<5$; or vi) multiorgan failure. Furthermore, all neonates had signs of neonatal encephalopathy (13).

Neonates with congenital malformation, trauma, metabolic or infective diseases, and patients born prior to reaching a 36-week gestational age, were excluded from this study. Five healthy term infants ( 3 males, 2 females; age range, 0-15 days) were recruited in the control group. The patients underwent MRI examination for scalp hematoma or slight neonatal jaundice.

MRI examinations. During the MRI procedures, all neonates were sedated with chloral hydrate $10 \mathrm{mg} / \mathrm{kg}$ (Sigma-Aldrich, St. Louis, MO, USA) orally, or rectally as a suppository. Vacuum pillows were used to prevent patients movement during MR examinations. Ear protection to noise exposure was provided by using neonatal ear muffs. A pediatrician was present throughout the investigation. The neonates were monitored by MR-compatible pulse oximetry during the examination procedure. For those neonates with severe encephalopathy who were in a coma or who were ventilator-dependent, hand-bag ventilator equipment was used.

All images in these series were obtained with superconducting magnets (MAGNETOM Avanto; Siemens Healthcare $\mathrm{GmbH}$, Erlangen, Germany) operating at a field-strength of $1.5 \mathrm{~T}$ magnet. All infants were in the axial plane. The total duration of the examination is $8 \mathrm{~min}$.

Conventional MRI methods. MRI protocols included $4.0 \mathrm{~mm}$ transverse and sagittal T1-weighted spin-echo sequences [repetition time (TR)/echo time (TE), 468/11 and 400/8.1 ms, respectively]; $4.0 \mathrm{~mm}$ transverse T2-weighted fast spin-echo sequence (TR/TE, 4000/101 ms); and an echo-planar imaging technique was used for diffusion weighted imaging (DWI; repetition time $\mathrm{msec} / \mathrm{echo}$ time $\mathrm{msec}=3300 / 93)$, with a 180x180 mm field of view, $4.0 \mathrm{~mm}$ section thickness and $\mathrm{b}$ values of 0 and $1,000 \mathrm{sec} / \mathrm{mm}^{2}$.

Proton MR spectroscopy methods. MR spectroscopy was performed similarly to the routine MR protocol. Spectra were acquired by using a single-voxel technique to select a single volume of interest (voxel dimensions, $10 \mathrm{~mm}^{3}, 1 \mathrm{ml}$ ) in the left or right basal ganglia and thalamus, as reported previously. The basal ganglia and thalamus are most sensitive to the effects of acute anoxia (14). This single voxel can reflect the global disturbances, such as cortical gray matter and the frontal and occipital white matter. Placement was performed carefully to avoid contact with cerebral spinal fluid.

The parameters of single-voxel MR spectroscopy were as follows: TR, 1,500 ms; TE, $35 \mathrm{~ms}$; 128 signals acquired; and 8NEX. Water suppression was achieved by applying chemical shift selective saturation pulses. Metabolites of biologic importance, such as $\mathrm{N}$-acetylaspartate (NAA), creatine $(\mathrm{Cr})$, and choline (Cho) peaks were identified at 2.02, 3.02 and 3.24 ppm, respectively. When present, lactate (Lac) was identified as a doublet at $1.33 \mathrm{ppm}$.

Automated curve was performed on an MRI operator console by using proprietary software (Siemens Healthcare $\mathrm{GmbH}$ ). Manual phase adjustment was applied if necessary. In all cases, peak surface area was used to calculate metabolite ratios for metabolite quantification. As for Lac, the combined area under the doublet was used for calculations.

Conventional MRI. The MR images obtained in all neonates were analyzed independently by a senior radiologist (Dr. Dehang Wang) who was experienced in neonatal neuroimaging, blinded to the clinical outcomes and MR spectroscopy information, and who analyzed the images according to MRI scores (15). This score (range, 0-22; Table I) was generated according to a report on MRI and DWI abnormalities in neonates with HIE (16). The following predefined structures were analyzed: Basal ganglia regions (including thalamus); cerebral cortex; periventricular and subcortical white matter; corpus callosum; and brainstem. For each structure, any MR signal intensity abnormality irrelevant to injury was documented as a high-signal intensity (SI) lesion on T1 weighted image (WI).

MR spectroscopy quantifications. The spectra was reviewed by an MR specialist (Dr. Genji Bo) who had 10 years of experience in interpreting brain MR spectroscopy and who was blinded to the clinical outcomes and the MR images. All ${ }^{1} \mathrm{H}-\mathrm{MR}$ spectroscopic data were included in the analysis $(n=29)$ and all findings were pooled. $\mathrm{Cr}$ was used as a reference to measure the ratios of $\mathrm{NAA} / \mathrm{Cr}, \mathrm{Cho} / \mathrm{Cr}$ and $\mathrm{Lac} / \mathrm{Cr}$. These ratios were compared in the 29 neonates to select a perspective indicator of the neonates with HIE.

Statistical analysis. Data obtained were expressed as the mean \pm standard deviation, and all data were analyzed using SPSS version 15.0 statistical software (SPSS, Inc., Chicago, IL, USA). $\mathrm{P}<0.05$ were considered to indicate a statistically significant difference. The comparison between the control and HIE group was performed by a two-tailed t-test. The paired comparisons among the control group and each HIE group were performed by two-way analysis of variance and the Student-Newman-Keuls method.

\section{Results}

Clinical characteristics. The neurologic examinations were routinely performed by the pediatricians in charge of the neonates. Knowledge of the outcomes, including seizures, sensory impairment and encephalodysplasia, were collected from the medical records by these pediatricians.

Two cases with severe HIE succumbed to irreversible cerebral injury and withdrawal of the life-sustaining treatments. The decision to withdraw treatment was based on the combination results of clinical examination, cerebral MRI, ${ }^{1} \mathrm{H}-\mathrm{MR}$ spectroscopy and electroencephalography, as reported previously (17). The remaining cases received suitable HIE treatment. The average number of days spent in hospital were as follows: Mild to moderate group, 11.5 days (range, 6-18 days); severe group, 19.6 days (range, 8-25 days). Four cases of severe HIE neonates still had weak nerve reaction upon discharge from the hospital. The neurological system symptoms of the remaining participants disappeared prior to leaving the hospital. No abnormal nervous system signs were detected in the control group. 
Table I. Magnetic resonance imaging score criteria.

\begin{tabular}{|c|c|}
\hline Category & Score criteria \\
\hline A & Brain swelling: 0 , Not present; 2, present \\
\hline $\mathrm{B}$ & Grey/white matter differentiation: 0 , Present; 1 , absent in one localization; 2 , absent in more than one localization \\
\hline $\mathrm{C}$ & High signal in the posterior limb of the internal capsule on T1WI: 0 , Normal; 1 , mild decrease; 2 , absent \\
\hline $\mathrm{D}$ & Hyperintensity on T1WI sequences on PP and T: 0 , None; 1 , one localization; 2 , more than one localization \\
\hline $\mathrm{E}$ & Hyperintensity on T2 sequences on PP and T: 0 , None; 1, one localization; 2, more than one localization \\
\hline $\mathrm{F}$ & Brain stem abnormalities on T1WI and/or T2WI sequences: 0, None; 1, present \\
\hline G & Cortex abnormalities on T1 and/or T2 sequences: 0 , None; 1 , one localization; 2 , more than one localization \\
\hline $\mathrm{H}$ & White matter petechial abnormalities: 0 , None; 1 , one localization; 2 , more than one localization \\
\hline I & Subarachnoid hemorrhages: 0 , None; 1 , present \\
\hline $\mathrm{J}$ & White-matter abnormalities in DWI: 0 , None; 1 , one localization; 2 , more than one localization \\
\hline $\mathrm{K}$ & Basal ganglia abnormalities in DWI: 0 , None; 1 , one localization; 2 , more than one localization \\
\hline $\mathrm{L}$ & Cerebral cortex abnormalities in DWI: 0 , None; 1 , one localization; 2 , more than one localization \\
\hline
\end{tabular}

T1WI, T1 weighted image; T2WI, T2 weighted image; DWI, diffusion weighted imaging; PP, putamen and pallidum; T, thalamus.

Table II. Clinical data and magnetic resonance findings of all participants in the study.

\begin{tabular}{|c|c|c|c|c|c|c|}
\hline $\begin{array}{l}\text { Case } \\
\text { no. }\end{array}$ & Gender & $\begin{array}{l}\text { Age } \\
\text { (days) }\end{array}$ & $\begin{array}{l}\text { Number of } \\
\text { PWML }\end{array}$ & $\begin{array}{c}\text { Signal on DWI } \\
\text { (reduced diffusion) }\end{array}$ & Body weight (g) & Outcome \\
\hline 1 & M & 3 & 4 & Yes & 3350 & Minor or moderate abnormalities \\
\hline 2 & M & 7 & 13 & Yes & 3000 & Minor or moderate abnormalities \\
\hline 3 & M & 1 & 0 & No & 3630 & No abnormalities \\
\hline 4 & $\mathrm{~F}$ & 3 & 0 & No & 3070 & No abnormalities \\
\hline 5 & M & 15 & 0 & No & 3040 & No abnormalities \\
\hline 6 & M & 5 & 6 & Yes & 4000 & Minor or moderate abnormalities \\
\hline 7 & M & 10 & 8 & No & 3620 & Minor or moderate abnormalities \\
\hline 8 & M & 2 & 35 & Yes & 2380 & Mortality on day 6 \\
\hline 9 & $\mathrm{~F}$ & 3 & 13 & Yes & 3760 & Severe abnormalities \\
\hline 10 & $\mathrm{~F}$ & 1 & 8 & Yes & 3510 & Minor or moderate abnormalities \\
\hline 11 & M & 3 & 1 & Yes & 2800 & No abnormalities \\
\hline 12 & M & 1 & 1 & Yes & 3710 & No abnormalities \\
\hline 13 & M & 3 & 12 & Yes & 3560 & Minor or moderate abnormalities \\
\hline 14 & $\mathrm{~F}$ & 5 & 6 & Yes & 3450 & No abnormalities \\
\hline 15 & M & 1 & 0 & Yes & 2565 & No abnormalities \\
\hline 16 & M & 12 & 2 & Yes & 2570 & Minor or moderate abnormalities \\
\hline 17 & $\mathrm{~F}$ & 11 & 20 & Yes & 2850 & Severe abnormalities \\
\hline 18 & $\mathrm{~F}$ & 11 & 14 & Yes & 2560 & Severe abnormalities \\
\hline 19 & M & 8 & 2 & Yes & 4480 & No abnormalities \\
\hline 20 & $\mathrm{~F}$ & 4 & 0 & Yes & 3100 & No abnormalities \\
\hline 21 & M & 1 & 24 & Yes & 3000 & Severe abnormalities \\
\hline 22 & $\mathrm{~F}$ & 5 & 59 & Yes & 2050 & Mortality on day 12 \\
\hline 23 & M & 8 & 1 & Yes & 3570 & No abnormalities \\
\hline 24 & M & 15 & 1 & No & 3450 & No abnormalities \\
\hline 25 & M & 3 & 1 & Yes & 2860 & No abnormalities \\
\hline 26 & M & 6 & 11 & Yes & 3600 & Minor or moderate abnormalities \\
\hline 27 & M & 10 & 5 & Yes & 4000 & Minor or moderate abnormalities \\
\hline 28 & $\mathrm{~F}$ & 3 & 1 & Yes & 2850 & No abnormalities \\
\hline 29 & M & 2 & 13 & Yes & 3600 & Minor or moderate abnormalities \\
\hline
\end{tabular}

PWML, punctate white matter lesions; DWI, diffusion weighted image; M, male; F, female. 
A

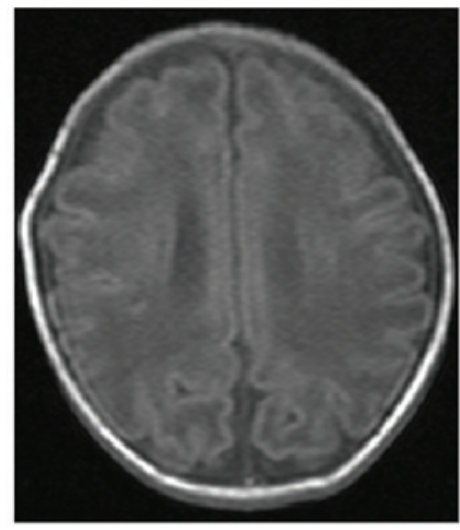

B

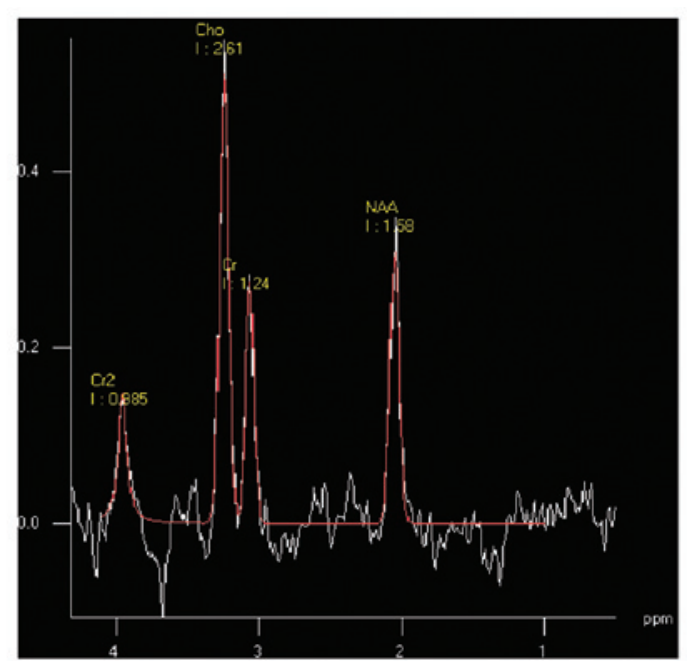

Figure 1. (A) Mild hypoxic-ischemic encephalopathy neonate at 3 days of age; transverse T1 weighted image showed subcortical punctate hyperintensity. (B) Magnetic resonance spectroscopy (1500/35 ms) images of the basal ganglia; low levels of N-acetylaspartate were detected.

A

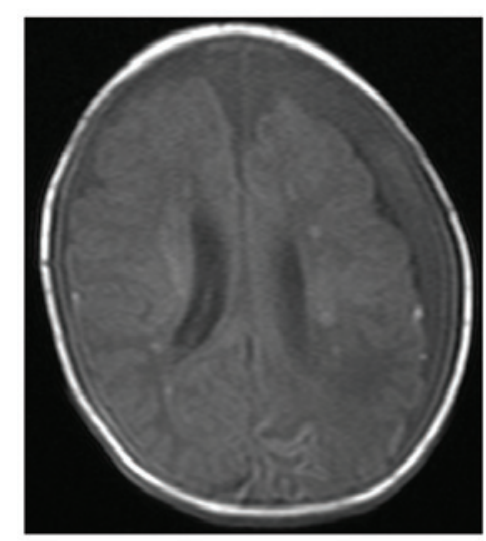

B

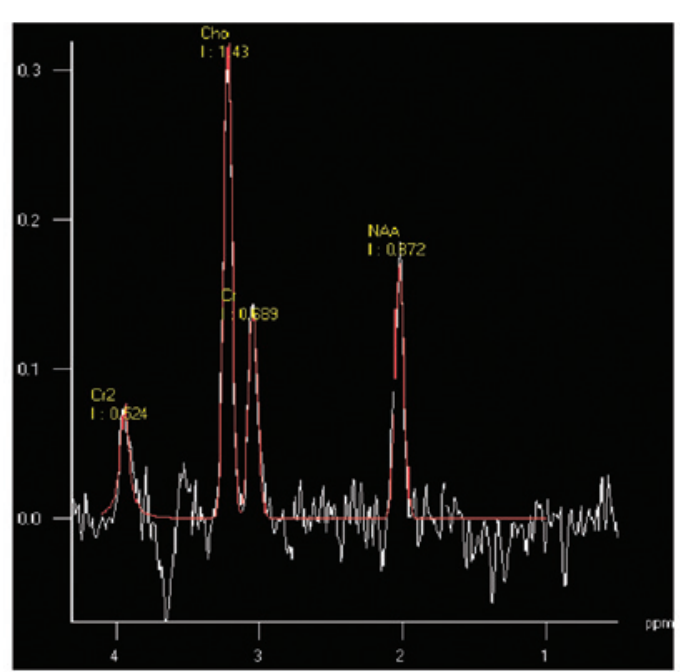

Figure 2. (A) Moderate hypoxic-ischemic encephalopathy neonate at 24 days of age. Transverse T1 weighted image showed multiple punctate hyperintensity surrounding the ventricle. (B) Magnetic resonance spectroscopy (1500/35 ms) images of the basal ganglia; low levels of N-acetylaspartate were detected.

Neonatal HIE severity was graded clinically according to Sarnat-Sarnat classification (18). The general condition of the HIE neonates were as follows (Table II): Mild to moderate (stages I-II), 13 cases; severe (stage III), 11 cases.

MR imaging data. According to the MRI data, abnormal imaging was not identified in the control group. Four types of images in HIE groups were observed. Cerebral hyperintensity lesions (according to the site of lesions, two subtypes could be detected), cortex and/or watershed area lesions (Fig. 1) and periventricular white matter lesions (Fig. 2) were detected. These characteristic abnormalities were visible as early as the first day of life. However, these lesions identified by punctuate hypersignal on T1WI and hyposignal on T2WI were assumed to be petechial hemorrhage, gliotic scarring, scarring or mineralization, which are impossible to distinguish on T1- and T2WI $(19,20)$. Longitudinal imaging showed a decrease in the number of punctate white matter lesions (PWML) over time, without hypersignal of PWML on T1WI, suggesting hemorrhage; a number of PWML did not change hypersignal on T1WI, suggesting early gliosis (21). In addition, basal ganglia, thalamic, corpus callosum or mesencephalic injury (Fig. 3) was identified on conventional and diffusion-weighted MR images. Furthermore, subarachnoid haemorrhage, in which short T1 high signal was manifested in the posterior sagittal sinus, horizontal sinus, cerebellar tentorium or confluence of sinus (Fig. 4), was detected. Finally, intraventricular haemorrhage (Fig. 5) could be observed.

Compared with the images of the two HIE groups, punctate hyperintensity lesions on T1WI in the cortex or subcortical white matter and brain edema on T2WI were visually similar. Abnormal SI of the thalamus, corpus callosum or brain stem on conventional and diffusion-weighted MR images were significantly different in the severe group $(\mathrm{P}=0.001)$. Abnormal SI within the basal ganglia and thalami may predict the severity outcome.

Unilateral parenchymal hemorrhage was identified in four infants in the HIE group. The mean number of PWML 
A

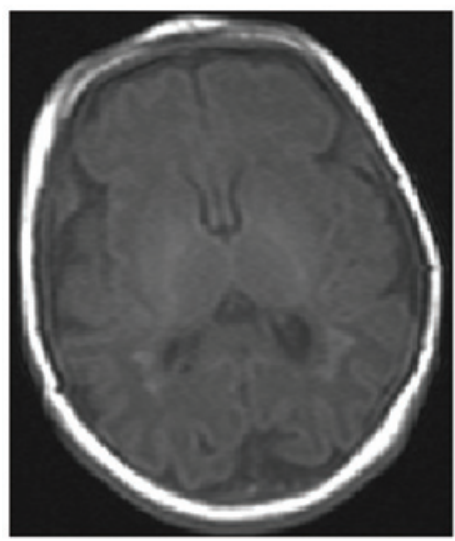

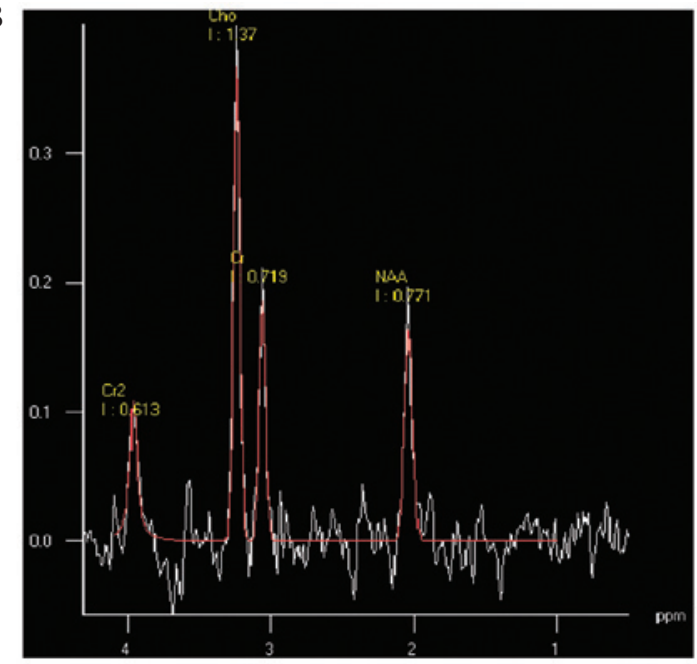

Figure 3. (A) Severe hypoxic-ischemic encephalopathy neonate at 1 day of age. Transverse T1 weighted image showed multiple punctate hyperintensity surrounding the ventricle and low-signal-intensity areas on the corpus callosum. (B) Magnetic resonance spectroscopy (1500/35 ms) images of the basal ganglia; low levels of $\mathrm{N}$-acetylaspartate were detected.

A

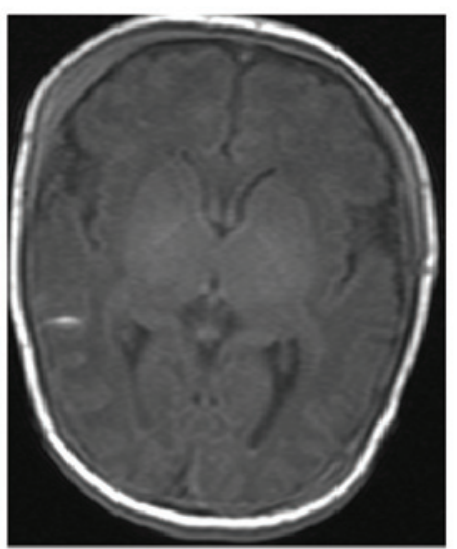

B

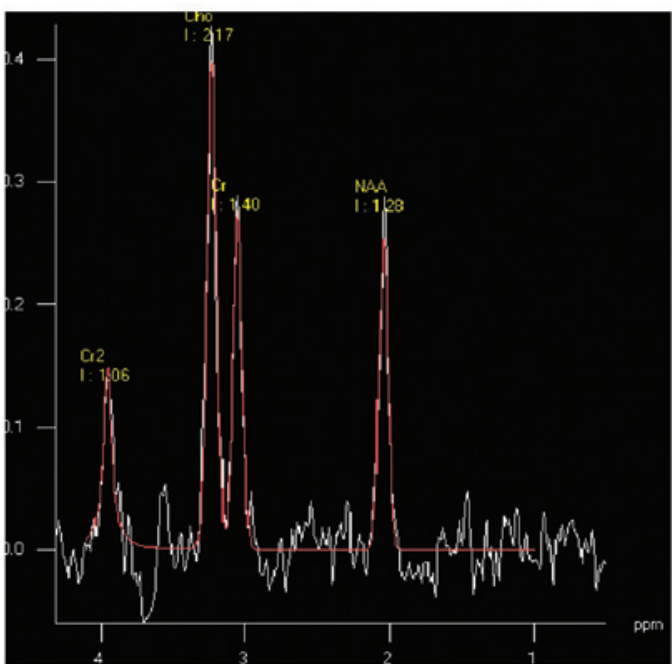

Figure 4. (A) Mild hypoxic-ischemic encephalopathy neonate at 14 days of age; transverse T1 weighted image showed subarachnoid hemorrhage. (B) Magnetic resonance spectroscopy $(1500 / 35 \mathrm{~ms})$ images of the basal ganglia; low levels of N-acetylaspartate were detected.

A

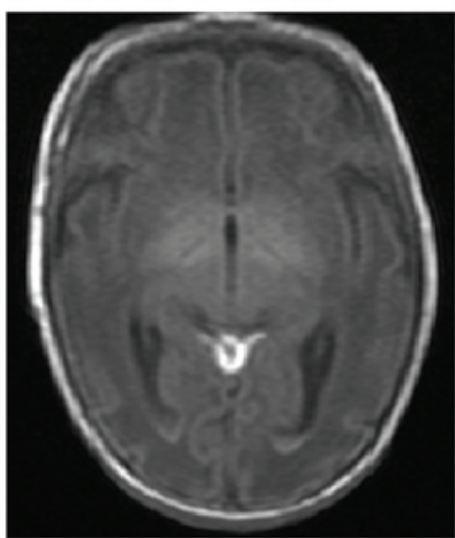

B

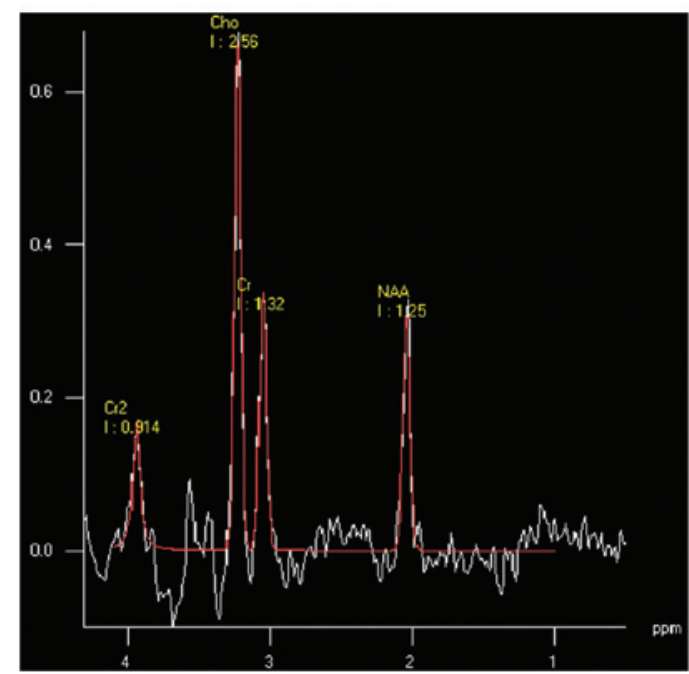

Figure 5. (A) Mild hypoxic-ischemic encephalopathy neonate at 8 days of age. Transverse T1 weighted image showed subarachnoid and intraventricular hemorrhage. (B) Magnetic resonance spectroscopy $(1500 / 35 \mathrm{~ms})$ images of the basal ganglia; low levels of N-acetylaspartate were detected. 
Table III. Magnetic resonance scores for all participants.

\begin{tabular}{|c|c|c|c|c|c|c|c|c|c|c|c|c|c|c|}
\hline \multirow[b]{2}{*}{ Case no. } & \multicolumn{12}{|c|}{ Category } & \multirow[b]{2}{*}{ Score } & \multirow[b]{2}{*}{ Stage } \\
\hline & A & B & $\mathrm{C}$ & $\mathrm{D}$ & E & $\mathrm{F}$ & G & $\mathrm{H}$ & I & $\mathrm{J}$ & $\mathrm{K}$ & $\mathrm{L}$ & & \\
\hline 1 & 2 & 0 & 2 & 0 & 0 & 0 & 0 & 2 & 1 & 2 & 0 & 0 & 9 & $1-2$ \\
\hline 2 & 2 & 0 & 2 & 0 & 0 & 0 & 0 & 2 & 0 & 2 & 0 & 0 & 8 & $1-2$ \\
\hline 3 & 0 & 0 & 0 & 0 & 0 & 0 & 0 & 0 & 0 & 0 & 0 & 0 & 0 & 0 \\
\hline 4 & 0 & 0 & 0 & 0 & 0 & 0 & 0 & 0 & 0 & 0 & 0 & 0 & 0 & 0 \\
\hline 5 & 0 & 0 & 0 & 0 & 0 & 0 & 0 & 0 & 0 & 0 & 0 & 0 & 0 & 0 \\
\hline 6 & 0 & 0 & 1 & 0 & 0 & 0 & 0 & 2 & 1 & 2 & 0 & 0 & 5 & 3 \\
\hline 7 & 0 & 0 & 2 & 0 & 0 & 0 & 0 & 2 & 0 & 0 & 0 & 0 & 4 & $1-2$ \\
\hline 8 & 2 & 0 & 2 & 0 & 0 & 0 & 0 & 2 & 0 & 2 & 2 & 0 & 10 & 3 \\
\hline 9 & 2 & 2 & 1 & 0 & 0 & 0 & 2 & 2 & 0 & 2 & 2 & 2 & 15 & 3 \\
\hline 10 & 0 & 0 & 2 & 0 & 0 & 0 & 0 & 2 & 0 & 2 & 0 & 0 & 6 & $1-2$ \\
\hline 11 & 2 & 0 & 2 & 0 & 0 & 0 & 0 & 1 & 1 & 1 & 0 & 0 & 7 & $1-2$ \\
\hline 12 & 2 & 1 & 2 & 0 & 0 & 0 & 0 & 1 & 0 & 1 & 0 & 0 & 6 & $1-2$ \\
\hline 13 & 2 & 2 & 2 & 0 & 2 & 1 & 0 & 2 & 0 & 2 & 2 & 0 & 15 & 3 \\
\hline 14 & 2 & 0 & 2 & 0 & 0 & 0 & 2 & 2 & 1 & 2 & 0 & 2 & 13 & 3 \\
\hline 15 & 0 & 0 & 0 & 0 & 0 & 0 & 0 & 0 & 0 & 0 & 0 & 0 & 0 & 0 \\
\hline 16 & 0 & 0 & 1 & 0 & 0 & 0 & 0 & 2 & 0 & 2 & 0 & 0 & 5 & $1-2$ \\
\hline 17 & 2 & 0 & 2 & 0 & 0 & 0 & 0 & 2 & 0 & 2 & 0 & 0 & 8 & 3 \\
\hline 18 & 0 & 0 & 0 & 0 & 0 & 0 & 2 & 2 & 1 & 2 & 0 & 2 & 9 & 3 \\
\hline 19 & 2 & 0 & 2 & 0 & 0 & 0 & 0 & 1 & 0 & 1 & 0 & 0 & 4 & $1-2$ \\
\hline 20 & 0 & 0 & 0 & 0 & 0 & 0 & 0 & 0 & 0 & 0 & 0 & 0 & 0 & 0 \\
\hline 21 & 2 & 0 & 2 & 0 & 0 & 0 & 2 & 2 & 1 & 2 & 2 & 2 & 15 & 3 \\
\hline 22 & 2 & 0 & 0 & 0 & 0 & 0 & 1 & 2 & 0 & 2 & 0 & 1 & 8 & 3 \\
\hline 23 & 2 & 2 & 2 & 0 & 0 & 0 & 1 & 1 & 1 & 1 & 0 & 1 & 11 & 3 \\
\hline 24 & 2 & 2 & 2 & 0 & 0 & 0 & 0 & 1 & 1 & 1 & 0 & 0 & 9 & 3 \\
\hline 25 & 0 & 0 & 1 & 0 & 0 & 0 & 0 & 1 & 0 & 1 & 0 & 0 & 3 & $1-2$ \\
\hline 26 & 2 & 0 & 1 & 0 & 0 & 0 & 0 & 2 & 0 & 2 & 0 & 0 & 7 & $1-2$ \\
\hline 27 & 2 & 1 & 0 & 0 & 0 & 0 & 0 & 2 & 1 & 0 & 0 & 0 & 6 & $1-2$ \\
\hline 28 & 2 & 2 & 2 & 0 & 0 & 0 & 0 & 1 & 0 & 1 & 0 & 0 & 8 & $1-2$ \\
\hline 29 & 2 & 0 & 2 & 0 & 0 & 0 & 0 & 2 & 0 & 2 & 0 & 0 & 8 & $1-2$ \\
\hline
\end{tabular}

Table IV. Quantitative analyses of the metabolic compounds used in the study.

\begin{tabular}{lrccc}
\hline Groups & Number & NAA/Cr & Cho/Cr & Lac/Cr \\
\hline Control & 5 & $1.60 \pm 0.47$ & $1.67 \pm 0.81$ & - \\
HIE & 24 & $1.09 \pm 0.41$ & $2.12 \pm 0.87$ & $0.14 \pm 0.26$ \\
Mild to & 13 & $1.23 \pm 0.35$ & $1.84 \pm 0.37$ & $0.03 \pm 0.06$ \\
moderate & & & & \\
Severe & 11 & $0.97 \pm 0.41$ & $2.43 \pm 1.16$ & $0.26 \pm 0.34$ \\
\hline
\end{tabular}

Data was expressed as the mean \pm standard deviation. HIE, hypoxic-ischemic encephalopathy; NAA, N-acetylaspartate; Cr, creatinine; Cho, choline; Lac, lactate.

in the mild to moderate group (stages I-II) was $5.38 \pm 4.68$ (range, 1-13). The mean number of PWML in the severe group (stage III) was 16.82 \pm 17.66 (range, 4-59). A significant difference was identified between these two groups in regard to the number of PWML $(\mathrm{P}=0.035)$. The majority of PWML were identified close to the medullary veins and showed restricted diffusion on early MRI; two infants did not have restricted diffusion on early MRI (identified as hyposignal on DWI).

The neonatal MR score was obtained from the scan images. Points were awarded for the presence of brain swelling and abnormal SI within the cortex, subcortical and periventricular white matter, basal ganglia and thalamus, brain stem, and from the posterior limb of the internal capsule. The MR scores (Table III) of the two HIE groups were compared. The mean MR imaging score was $6.20 \pm 1.75$ for cases of stage I-II and $9.78 \pm 3.64$ for cases of stage III. There was a significant difference between the two groups $(\mathrm{P}=0.009)$.

MR spectroscopy. In the control and HIE groups, the peaks of metabolites of biologic importance, such as NAA (2.02 ppm), $\mathrm{Cr}$ (3.02 ppm) and Cho (3.24 ppm), were identified. The $\mathrm{Cr}$ was used as a reference to measure NAA/Cr, $\mathrm{Cho} / \mathrm{Cr}$ and $\mathrm{Lac} / \mathrm{Cr}$ ratios (Table IV). In the control group, the values of $\mathrm{NAA} / \mathrm{Cr}$ and $\mathrm{Cho} / \mathrm{Cr}$ were $1.60 \pm 0.47$ and $1.67 \pm 0.81$, respectively, while 
Table V. Comparison of magnetic resonance spectroscopy metabolites between control and HIE groups.

\begin{tabular}{lccc}
\hline Groups & NAA/Cr P & Cho/Cr P & Lac/Cr P \\
\hline Control vs. HIE & 0.015 & 0.029 & 0.020 \\
$\begin{array}{l}\text { Control vs. Mild } \\
\text { to moderate }\end{array}$ & 0.016 & 0.040 & 0.048 \\
$\begin{array}{l}\text { Control vs. severe } \\
\text { Mild to moderate }\end{array}$ & 0.010 & 0.010 & 0.050 \\
vs. severe & 0.171 & 0.138 & 0.380 \\
\hline
\end{tabular}

The t-test was used to compare the quantity of the metabolic compounds among the control and HIE groups. $\mathrm{P}<0.05$ was considered to indicate a statistically significant difference. HIE, hypoxic-ischemic encephalopathy; NAA, N-acetylaspartate; Cr, creatinine; Cho, choline; Lac, lactate; P, P-values.

Lac/Cr was not detected. In the HIE groups, Lac was identified as a doublet at $1.33 \mathrm{ppm}$, and the values of NAA/Cr, $\mathrm{Cho} / \mathrm{Cr}$ and $\mathrm{Lac} / \mathrm{Cr}$ were $1.09 \pm 0.4,2.12 \pm 0.87$ and $0.14 \pm 0.26$, respectively. In the mild to moderate group (stages I-II), the ratios showed $\mathrm{NAA} / \mathrm{Cr}$ of $1.23 \pm 0.35, \mathrm{Cho} / \mathrm{Cr}$ of $1.84 \pm 0.37$ and $\mathrm{Lac} / \mathrm{Cr}$ of $0.03 \pm 0.06$. In the severe group (stage III), the ratios showed NAA/Cr of $0.97 \pm 0.41, \mathrm{Cho} / \mathrm{Cr}$ of $2.43 \pm 1.16$ and $\mathrm{Lac} / \mathrm{Cr}$ of $0.26 \pm 0.34$.

Between control and HIE groups, the differences of $\mathrm{NAA} / \mathrm{Cr}, \mathrm{Cho} / \mathrm{Cr}$ and $\mathrm{Lac} / \mathrm{Cr}$ in the basal ganglia and thalamus were statistically significant $(\mathrm{P}<0.05)$. Multiple comparisons were performed among control and HIE groups (Table V). The differences of NAA/Cr, Cho $/ \mathrm{Cr}$ and $\mathrm{Lac} / \mathrm{Cr}$ between the control and mild to moderate groups, and control and severe groups, were statistically significant $(\mathrm{P}<0.05)$. The differences of NAA/Cr, $\mathrm{Cho} / \mathrm{Cr}$ and $\mathrm{Lac} / \mathrm{Cr}$ between mild to moderate and severe groups was not statistically significant $(\mathrm{P}>0.05)$.

\section{Discussion}

MR imaging technology, which is thought to show brain morphology at a high resolution in the clinic, has been developed rapidly in the past decades. It is superior to cerebral CT and ultrasound examination in displaying lesions in the basal ganglia or deep white matter, and multi-cystic encephalomalacia around the ventricle (22).

T1WI could provide essential information for the diagnosis and depicting typical MRI features of hypoxic-ischemic injury (3,5-6). The imaging pattern of HIE has been classified into three types $(4,23)$; parasagittal lesions, involving cortico-subcortical regions, profound lesions located in the basal ganglia or thalamus, and multi-cystic encephalomalacia. Parasagittal lesions are typically associated with milder HIE (24). In the present study, the T1 images in the mild to moderate $(n=13)$ and severe group $(n=11)$ were similar, with punctate hyperintensity in the cortex or subcortical white matter $(\mathrm{P}>0.05)$. Profound lesions in the basal ganglia and thalamus are often associated with serious HIE (25). The results in the present study showed unequivocally that lesions in the basal ganglia and thalamus were associated with the severe group. Finally, multi-cystic encephalomalacia are typically connected with an end-stage finding of severe HIE. Multiple cysts in the brain were not detected in the current study.

Previously, a meta-analysis (14) reported the prognostic utilities of various quantitative cerebral MR biomarkers in neonatal encephalopathy. Thirty-two studies were included that were performed between January 1990 and July 2008. Regarding predicting adverse outcome, T1WIs during the first 30 days had a pooled sensitivity of $91 \%$ (95\% confidence interval [CI], 87-94\%). The pattern of injury identified with T1WI may provide diagnostic and prognostic information for neonatal encephalopathy $(20,14)$. Infants who show abnormal SI in the basal ganglia/thalami typically undergo an adverse outcome (12-26). The changes in routine T1WIs are characteristic, but a question is put forward as to whether MRS biomarkers may be available in T1WI in the evaluation of infants.

MRS is a non-invasive technique that allows real-time analysis of metabolites in the human brain (27). Cho is a marker for membrane synthesis and $\mathrm{Cr}(3.0 \mathrm{ppm})$ is chosen as the reference because of its stability. Due to the rapid growth of the membranes in the neonatal brain, the NAA (2.01 ppm) level is much lower than Cho (3.02 ppm) (28). Reportedly, Lac $(1.33 \mathrm{ppm})$ is not present in great quantities in normal neonates and is rarely detected by MRS (11). In the present study, Lac in the control group was not observed.

The ascent of Lac/Cr, presumably because of energy failure and the necessity to metabolize glucose anaerobically, was not marked as elucidated by Hanrahan et al (12), in contrast to the results of the present study. It seems likely that this difference of results is related to the time of the MRS examination with respect to the hypoxic-ischemic event. The mean time from injury to MRS in patients in the current study was 7 days; for patients in Hanrahan et al (12), the mean time was $<24 \mathrm{~h}$. The precise time at which lactate levels become lower after hypoxic-ischemic injury in neonates is unknown. Indeed, in the study by Xu and Vigneron (29), although the presence of lactate persisted, the Lac level always dropped on follow-up spectra performed weeks after the injury. Hence, it can be suggested that the Lac level would have been higher if the patients had been studied earlier following perinatal hypoxic-ischaemic injury in the present study. The results in the present study were consistent with those of Barkovich et al (30) and Alderliesten et al (31), who found associations with NAA levels in HIE. Similarly, the patients in the study by Barkovich et al (30) experienced injury within an average of 7 days prior to MRS and those of Alderliesten et al (31) experienced a hypoxic-ischemic event at an average of 6 days. Surprisingly, no statistically significant differences in NAA/Cr and $\mathrm{Lac} / \mathrm{Cr}$ were identified between the mild to moderate and severe group. In comparison with MR performances, results of proton MRS had a number of limitations in distinguishing mild from moderate to severe injury.

In conclusion, ${ }^{1} \mathrm{H}-\mathrm{MRS}$ is a useful technique for distinguishing between HIE and normal newborns; however, with regard to differentiating between grades, ${ }^{1} \mathrm{H}$-MRS should be interpreted in conjunction with performances on T1WI. 


\section{References}

1. Dilenge ME, Majnemer A and Shevell MI: Long-term developmental outcome of asphyxiated term neonates. J Child Neurol 16: 781-792, 2001.

2. Yin XJ, Wei W, Han T, Shang MX, Han X, Chai YN and Feng ZC: Value of amplitude-integrated electroencephalograph in early diagnosis and prognosis prediction of neonatal hypoxic-ischemic encephalopathy. Int J Clin Exp Med 7: 1099-1104, 2014.

3. Jadas V, Brasseur-Daudruy M, Chollat C, Pellerin L, Devaux AM and Marret S; et le réseau de périnatalité de Haute-Normandie: The contribution of the clinical examination, electroencephalogram and brain MRI in assessing the prognosis in term newborns with neonatal encephalopathy. A cohort of 30 newborns before the introduction of treatment with hypothermia Arch Pediatr 21: 125-133, 2014 (In French).

4. Sie LT, van der Knaap MS, Oosting J, de Vries LS, Lafeber HN and Valk J: MR patterns of hypoxic-ischemic brain damage after prenatal, perinatal or postnatal asphyxia. Neuropediatrics 31:128-136, 2000.

5. Liauw L, Palm-Meinders IH, van der Grond J, Leijser LM, le Cessie S, Laan LA, Heeres BC, van Buchem MA and van Wezel-Meijler G: Differentiating normal myelination from hypoxic-ischemic encephalopathy on T1-weighted MR Images: A new approach. AJNR Am J Neuroradiol 28: 660-665, 2007.

6. Liauw L, van der Grond J, van den Berg-Huysmans AA, Laan LA, van Buchem MA and van Wezel-Meijler G: Is there a way to predict outcome in (near) term neonates with hypoxic-ischemic encephalopathy based on MR imaging? AJNR Am J Neuroradiol 29: 1789-1794, 2008.

7. Ancora G, Testa C, Grandi S, Tonon C, Sbravati F, Savini S, Manners DN, Gramegna LL, Tani G, Malucelli E, et al: Prognostic value of brain proton $\mathrm{mr}$ spectroscopy and diffusion tensor imaging in newborns with hypoxic-ischemic encephalopathy treated by brain cooling. Neuroradiology 55: 1017-1025, 2013.

8. Barkovich AJ, Baranski K, Vigneron D, Partridge JC, Hallam DK, Hajnal BL and Ferriero DM: Proton MR spectroscopy for the evaluation of brain injury in asphyxiated, term neonates. AJNR Am J Neuroradiol 20: 1399-1405, 1999.

9. Barkovich AJ, Westmark KD, Bedi HS, Partridge JC, Ferriero DM and Vigneron DB: Proton spectroscopy and diffusion imaging on the first day of life after perinatal asphyxia: Preliminary report. AJNR Am J Neuroradiol 22: 1786-1794, 2001.

10. Cheong JL, Cady EB, Penrice J, Wyatt JS, Cox IJ and Robertson NJ: Proton MR spectroscopy in neonates with perinatal cerebral hypoxic-ischemic injury: Metabolite peak-area ratios, relaxation times and absolute concentrations. AJNR Am J Neuroradiol 27: 1546-1554, 2006.

11. Zhu W, Zhong W, QI J, Yin P, Wang C and Chang L: Proton magnetic resonance spectroscopy in neonates with hypoxic ischemic injury and its prognostic value. Transl Res 152: 225-232, 2008.

12. Hanrahan JD, Sargentoni J, Azzopardi D, Manji K, Cowan FM, Rutherford MA, Cox IJ, Bell JD, Bryant DJ and Edwards AD: Cerebral metabolism within 18 hours of birth asphyxia: A proton magnetic resonance spectroscopy study. Pediatr Res 39: 584-590, 1996.

13. de Vries LS and Cowan FM. Evolving understanding of Hypoxic-ischemic Encephalopathy in the term infants. Semin Pediatr Neurol 16: 216-225, 2009.

14. Thayyil S, Chandrasekaran M, Taylor A, Bainbridge A, Cady EB, Chong WK, Murad S, Omar RZ and Robertson NJ: Cerebral magnetic resonance biomarkers in neonatal encephalopathy: A meta-analysis. Pediatrics 125: e382-e395, 2010.

15. Meyer-Witte S, Brissaud O, Brun M,Lamireau D, Bordessoules M and Chateil JF: Prognostic value of MR in term neonates with neonatal hypoxic-ischemic encephalopathy: MRI score and spectroscopy. About 26 cases. Arch Pediatr 15: 9-23, 2008 (In French).
16. Brissaud O, Amirault M, Villega F, Periot O, Chateil JF and Allard M: Efficiency of fractional anisotropy and apparent diffusion coefficient on diffusion tensor imaging in prognosis of neonates with hypoxic-ischemic encephalopathy: A methodologic prospective pilot study. AJNR Am J Neuroradiol 31: 282-287, 2010.

17. de Vries LS and Toet MC: Amplitude integrated electroencephalography in the full-term newborn. Clin Perinatol 33: 619-632, 2006.

18. Mia AH, Akter KR, Rouf MA, Islam MN, Hoque MM, Hossain MA and Chowdhury AK: Grading of perinatal asphyxia by clinical parameters and agreement between this grading and Sarnat \& Sarnat stages without measures. Mymensingh Med J 22: 807-813, 2013.

19. Dyet LE, Kennea N, Counsell SJ, Maalouf EF, Ajayi-Obe M, Duggan PJ, Harrison M, Allsop JM, Hajnal J, Herlihy AH, et al: Natural history of brain lesions in extremely preterm infants studied with serial magnetic resonance imaging from birth and neurodevelopmental assessment. Pediatrics 118: 536-548, 2006.

20. Ramenghi LA, Fumagalli M, Righini A, Bassi L, Groppo M, Parazzini C, Bianchini E, Triulzi F and Mosca F: Magnetic resonance imaging assessment of brain maturation in preterm neonates with punctate white matter lesions. Neuroradiology 49: 161-167, 2007.

21. Niwa T, de Vries LS, Benders MJ, Takahara T, Nikkels PG and Groenendaal F: Punctate white matter lesions in infants: New insights using susceptibility-weighted imaging. Neuroradiology 53: 669-679, 2011

22. van Laerhoven $H$, de Haan TR, Offringa M, Post B and van der Lee JH: Prognostic tests in term neonates with hypoxic-ischemic encephalopathy: A systematic review. Pediatrics 131: 88-98, 2013.

23. Gano D, Chau V, Poskitt KJ, Hill A, Roland E, Brant R, Chalmers $\mathrm{M}$ and Miller SP: Evolution of pattern of injury and quantitative MRI on days 1 and 3 in term newborns with hypoxic-ischemic encephalopathy. Pediatr Res 74: 82-87, 2013.

24. Nikas I, Dermentzoglou V, Theofanopoulou $M$ and Theodoropoulos V: Parasagittal lesions and ulegyria in hypoxic-ischemic encephalopathy: Neuroimaging findings and review of the pathogenesis. J Child Neurol 23: 51-58, 2008.

25. Wagner F, Haenggi MM, Wagner B, Weck A, Weisstanner C, Grunt S, Z'Graggen WJ, Gralla J, Wiest R and Verma RK: The value of susceptibility-weighted imaging (swi) in patients with non-neonatal hypoxic-ischemic encephalopathy. Resuscitation 88: 75-80, 2015.

26. Ment LR, Bada HS, Barnes P, Grant PE, Hirtz D, Papile LA, Pinto-Martin J, Rivkin M and Slovis TL: Practice parameter: Neuroimaging of the neonate: Report of the quality standards subcommittee of the American academy of neurology and the practice committee of the child neurology society. Neurology 58: 1726-1738, 2002.

27. Martinez-Biarge M, Diez-Sebastian J, Wusthoff CJ, Lawrence S, Aloysius A, Rutherford MA and Cowan FM: Feeding and communication impairments in infants with central grey matter lesions following perinatal hypoxic-ischaemic injury. Eur J Paediatr Neurol 16: 688-696, 2012.

28. Rutherford MA, Ward P and Malamatentiou C: Advanced MR techniques in the term-born neonate with perinatal brain injury. Semin Fetal Neonatal Med 10: 445-460, 2005.

29. Xu D and Vigneron D: Magnetic resonance spectroscopy imaging of the newborn brain-a technical review. Semin Perinatol 34: 20-27, 2010.

30. Barkovich AJ, Miller SP, Bartha A, Newton N, Hamrick SE, Mukherjee P, Glenn OA, Xu D, Partridge JC, Ferriero DM and Vigneron DB: MR imaging, MR spectroscopy and diffusion tensor imaging of sequential studies in neonates with encephalopathy. AJNR Am J Neuroradiol 27: 533-547, 2006.

31. Alderliesten T, de Vries LS, Benders MJ, Koopman $\mathrm{C}$ and Groenendaal F: MR imaging and outcome of term neonates with perinatal asphyxia: Value of diffusion-weighted MR imaging and ${ }^{1} \mathrm{H}$ MR spectroscopy. Radiology 261: 235-242, 2011. 